per os; auch bei der Züchtung war die Ausbeute an Kulturen eine geringere, und die Kulturen selbst zeigten eine Abnahme ihrer. Virulenz: durch fortgesetzte Thierpassagen wird also eine Abnahme der Vitalität und Virulenz des Danyszbacillus erzeugt. Zur Erklärung dieser für die Verwendung des Danyszbacillus als Epizootieerregers hochwichtigen Thatsache konnten in erster Linie folgende zwei Momente in Betracht gezogen werden: erstens die starke Säureproduktion und zweitens der nachtheilige Einfluss des sauren Magensaftes (wie bei der Cholerainfektion). Um diesen beiden Voraussetzungen zu genügen, benutzte ich erstens stark alkalischen $\mathrm{Ag}$ ar und zweitens, statt Kochsalzlösung, zur Aufschwemmung der Kultur eine conzentrirte Sodalösung. Dieses combinirte Verfahren hat sich in der That in vorzüglicher Weise bewährt: die Thiere gingen fast regelmässig nach gleicher Frist ein, und die dabei gewonnenen Kulturen behielten einen fast gleichen Virulenzgrad. Nach unseren Erfahrungen erwiesen sich junge Ratten viel empfindlicher dem Danyszbacillus gegenüber als erwachsene und eignen sich daher sehr, um die Virulenz des Danyszbacillus zu erhöhen. Wir konnten ausserdem die Beobachtung machen, dass die Rattenspezies (Rasse) einen gewissen Einfluss auf den Virulenzgrad auszuüben im Stande ist; gelingt es zum Beispiel, mittels Passage (durch Verfütterung) eine Kultur für weisse Ratten in ihrer Virulenz zu verstärken, so erweist sie sich dagegen minderwerthig für graue, resp. braune und vice versa. Es wäre deshalb rathsam, in Fällen, wo es auf eine Massenvertilgung ankommt, mittels Vorversuchen an einigen Exemplaren aus der lokalen Rattenbevölkerung eine für die betreffende Spezies adaptirte Kultur herzustellen. Unsere eigenen, wenn auch nicht im grossen Stil unternommenen Vertilgungsversuche haben uns überzengt, dass der Danyszbacillus durchaus pathogen für Ratten ist und mit Erfolg zur Rattenvertilgung verwendet werden kann.

Zum Schluss erlaube ich mir, meinem hochverehrten Chef, Herrn Dr. Ph. Blumenthal, für seine liebenswürdige Unterstützung bei meiner Arbeit meinen besten Dank auszusprechen.

IV. Aus dem bakteriologisch-chemischen Institut von Dr. Ph. Blumenthal in Moskau.

\section{Zur Frage der Rattenvertilgung mittels des Danyszbacillus.}

\section{Von Dr. J. Bronstein.}

Das rege Interesse, welches neuerdings der Frage nach der Rattenvertilgung mit dem von Prof. Danysz entdeckten Bacillus zugewendet wird, veranlasst mich, über meine eigenen Versuche kurz zu berichten.

Herrn Dr. D anysz sage ich hier für die mir zur Verfügung gestellte Reinkultur sowie für die schriftlich ertheilten Rathschläge meinen besten Dank.

In morphologischer und biologischer Hinsicht gehört der Danyszbacillus der Coligruppe an, unterscheidet sich aber von den übrigen Repräsentanten durch sein ziemlich stark ausgesprochenes Säurebildungsvermögen, welches sich am besten durch die Methode von Mankowski ${ }^{3}$ ) nachweisen lässt: durch die Kultur des Danyszbacillus auf Pilzagar nach Mankowski wird das Farbgemisch (Säurefuchsin + Indigokarmin) roth gefärbt, ganz wie durch eine Kultur von Typhus abdominalis, während alle itbrigen Coliarten dasselbe Farbgemisch grün färben. Durch Vorversuche konnten wir uns auch von der völligen Unschädlichkeit des Danyszbacillus für Laboratoriumsund Hausthiere - bei subkutaner Einführung wie bei Verfütterung per os - überzeugen. Versuche über die Pathogenität des Danyszbacillus wurden an ca. 60 Ratten von verschiedener Herkunft und Rasse angestellt. Mit der Verfütterung in üblicher Weise (von mit Kulturaufschwemmung in Kochsalzlösung getränkten Brodstücken) wurde erst nach siebentägigem Aufenthalt der Thiere im Laboratorium begonnen, um eventuell durch spontanen Tod der Thiere nicht irregeführt zu werden. Die Ratten starben nach Ablauf von 2-35 Tagen, die Mehrzahl jedoch zwischen 4-8 Tagen, wobei jedesmal der von Danysz und anderen Autoren angegebene Sektionsbefund, Milzschwellung und Hyperämie des Darms, nachgewiesen werden konnte. Aus dem Blute und den inneren Organen wurde der Danyszbacillus in Reinkultur gezüchtet, und zwar aus dem Organensaft in grösserer Menge als aus dem Blute. Aus Milzsaft gewonnene Kulturen erwiesen sich bedeutend virulenter als solche aus anderen Organen und Blut. Einige Thiere verendeten, wie erwähnt, schon am 2.-3. Tage, wahrscheinlich in Folge akuter Intoxikation, und es gelang bei diesen Thieren den Danyszbacillus weder aus Blut noch aus Organsaft zu züchten. Ausserdem wurde eine Anzahl von Ratten mit Leichentheilen von solchen, welche nach der üblichen Verfütterung per os eingegangen waren, gefüttert. Das Ergebniss war zwar ein positives, aber die Thiere erlagen erst viel später als bei der Fütterung

1) Seitdem noch ein Fall merkurieller Stomatitis ulcerosa mit den Spirochäten- und fusiformen Bazillen in den Geschwüren.

2) Revue de Médecine 1901, No. 4.

3) Centralblatt für Bakteriologie 1900, Bd. XXVII, S. 23.

(1)

